\title{
Arsenic removal from aqueous solutions by adsorption onto iron oxide/activated carbon magnetic composite
}

\author{
Shuhua Yao ${ }^{1}$, Ziru Liu ${ }^{2}$ and Zhongliang Shi ${ }^{*}$
}

\begin{abstract}
In this work the adsorption features of activated carbon and the magnetic properties of iron oxides were combined in a composite to produce magnetic adsorbent. Batch experiments were conducted to study the adsorption behavior of arsenate onto the synthetic magnetic adsorbent. The effects of initial solution pH, contact time, adsorbent dosage and co-existing anionic component on the adsorption of arsenate were investigated. The results showed that the removal percentage of arsenate could be over $95 \%$ in the conditions of adsorbent dosage $5.0 \mathrm{~g} / \mathrm{L}$, initial solution $\mathrm{pH}$ 3.0-8.0, and contact time $1 \mathrm{~h}$. Under the experimental conditions, phosphate and silicate caused greater decrease in arsenate removal percentage among the anions, and sulfate had almost no effect on the adsorption of arsenate. Kinetics study showed that the overall adsorption rate of arsenate was illustrated by the pseudo-second-order kinetic model. The applicability of the Langmuir and Freundlich models for the arsenate adsorption data was tested. Both the models adequately describe the experimental data. Moreover, the magnetic composite adsorbent could be easily recovered from the medium by an external magnetic field. It can therefore be potentially applied for the treatment of water contaminated by arsenate.
\end{abstract}

Keywords: Activated carbon, Iron oxide, Arsenic, Adsorption, Magnetic composite

\section{Introduction}

Recognized as a highly toxic element, arsenic (As) is abundant in our environment with both natural and anthropogenic sources [1]. Natural sources include the washout and erosion of arsenic-rich rocks and soils, which probably occur because of long-term geochemical changes. Anthropogenic sources include forestry, agricultural application of various pesticides, herbicides and fertilizers, and industrial effluents from metallurgy, electronics, mining, pharmaceuticals, glass processing, ceramic, dye and pesticides manufacturing, wood preservatives, petroleum refining, and landfill leaching $[2,3]$.

Arsenic occurs in both organic and inorganic forms in natural waters but organic arsenic is of little importance as it goes through biotransformation and detoxifies through methylation. Inorganic arsenic occurs in $-3,0,+3$, and +5 oxidation states in aquatic systems. The elemental state -3

\footnotetext{
*Correspondence: shzhl2000@163.com

'School of Applied Chemistry, Shenyang University of Chemical Technology, Shenyang, China

Full list of author information is available at the end of the article
}

and 0 are extremely rare whereas +3 and +5 oxidation states are commonly found in water systems depending on the prevailing redox conditions and $\mathrm{pH}$ conditions [4]. Under oxidizing conditions such as those prevailing in surface waters, the predominant species is pentavalent arsenic, which is mainly present with the oxyanionic forms $\left(\mathrm{H}_{2} \mathrm{AsO}_{4}^{-}, \mathrm{HAsO}_{4}{ }^{2-}\right)$ with $\mathrm{pK}_{\mathrm{a}}=2.19$; $\mathrm{pK}_{\mathrm{b}}=6.94$; respectively. On the other hand, under mildly reducing conditions such as in groundwater, As(III) is the thermodynamically stable form, which at $\mathrm{pH}$ values of most natural waters is present as non-ionic form of arsenious acid $\left(\mathrm{H}_{3} \mathrm{AsO}_{3}, \mathrm{pK}_{\mathrm{a}}=\right.$ 9.22) [5]. Inorganic species of arsenic [As(III) and $\mathrm{As}(\mathrm{V})]$ represent a potential threat to the environment, human health, and animal health due to their carcinogenic and other effects. Permanent arsenic intake can lead to chronic intoxication, and prolonged arsenic exposure can damage the central nervous system, liver, and skin and results in the appearance of diverse types of cancers, such as hyperkeratosis, lung, skin, and prostate cancers $[3,6]$.

Arsenic contamination has aroused attention due to groundwater levels in many parts of the world at much

\section{Biomed Central}

(C) 2014 Yao et al.; licensee BioMed Central Ltd. This is an Open Access article distributed under the terms of the Creative Commons Attribution License (http://creativecommons.org/licenses/by/2.0), which permits unrestricted use, distribution, and reproduction in any medium, provided the original work is properly credited. 
higher concentrations than the maximum contaminant level (MCL) of $10 \mu \mathrm{g} / \mathrm{L}$ for arsenic in drinking water recommended by the World Health Organization (WHO) [7]. Arsenic pollution has been reported recently in Bangladesh, Taiwan, Argentina, Mexico, Chile, China, Hungary, Thailand, USA, New Zealand, South Africa and India [8-10]. Therefore, an effective arsenic removal technology is thus highly desirable to provide safe drinking water to the affected people. Several methods have evolved over the years on the removal of arsenic present in water and wastewater. These are chemical precipitations, conventional coagulation, reverse osmosis, ion exchange and adsorption. One of which, adsorption method, is simple and cost-effective, thus has been widely used [11-15]. Among various absorbents, adsorption onto activated carbon has proven to be one of the most effective and reliable physicochemical treatment methodologies [16-19]. Due to its high surface area and porous structure it can efficiently adsorb gases and compounds dispersed or dissolved in liquids [20]. The adsorption of several organic contaminants in water, such as pesticides, phenols and chlorophenols, has recently been reported [21-23]. However, the application of activated carbon powders in water treatment system is limited because it is difficult to separate after the treatment process and reuse the tiny particles. The application of magnetic particle technology is one of the choices for field application of the activated carbon adsorbent. Magnetic particles can be used to adsorb contaminants from aqueous or gaseous effluents, and after adsorption, can be separated from the medium by a simple magnetic process.

The application of magnetic particle technology to solve environmental problems has received considerable attention in recent years [24-26]. To our knowledge, the preparation of magnetic composites based on activated carbon and iron oxide and their adsorption properties for arsenic have few been reported so far. In the present work, a series of magnetic composites having high surface area and high adsorption capacity were prepared based on activated carbon and iron oxide. The adsorption of $\operatorname{As}(\mathrm{V})$ on the prepared magnetic composites were investigated, the effects of different parameters such as contact time, initial $\mathrm{pH}$, adsorbent dosage and co-existing anionic component on adsorption process were studied, and the optimum adsorption isotherm as well as the rate of adsorption kinetics were found. Compared with other previous reports [27-30], the prime novelties of this work are (1) coating activated carbon onto iron oxide to prepare a magnetic adsorbent; (2) the regeneration of adsorbent was one of key steps to making adsorption technology for practical applications. The separation problem of the prepared adsorbent has been solved, after adsorption, the magnetic composite can be separated from the medium by a simple magnetic process.

\section{Experimental Chemicals}

All the chemicals used in the study were of analytical grade. All the solutions in the study were prepared using de-ionized water. All glassware was cleaned by rinsing with hydroxylamine hydrochloride, soaking in $10 \% \mathrm{HCl}$, and rinsing with de-ionized water.

$\mathrm{As}(\mathrm{V})$ stock solution $\left(1000 \mathrm{mg} \cdot \mathrm{L}^{-1}\right)$ was prepared by dissolving dehydrated sodium arsenate $\left(\mathrm{NaAsO}_{3}\right)$ in the de-ionized water. Dissolution of $\mathrm{NaAsO}_{3}$ also includes addition of $\mathrm{HCl}$. Further working solutions were freshly prepared from stock solution for each experimental run.

The activated carbon (AC) (AC12 $\times 40$, China Calgon) was used in this study. This kind of $\mathrm{AC}$ has moisture content of $1.2 \%$, ash content of $10.3 \%$, iodine values of $\mathrm{AC}$ adsorption of $1029 \mathrm{mg} / \mathrm{g}$, the hardness of $96.2 \%$, and the density of $480 \mathrm{~g} / \mathrm{L}$. Grain sizes of AC were: less than $1.7 \mathrm{~mm}$ in diameter and more than $0.425 \mathrm{~mm}$ in diameter. The virgin activated carbon was firstly rinsed with de-ionized water to remove dirties, and then was washed by $0.001 \mathrm{~mol} \cdot \mathrm{L}^{-1} \mathrm{HCl}$ solution to remove all salts precipitated in its pores. Then, the AC was repeatedly washed with de-ionized water to remove all traces of the acid. Subsequently, the washed activated carbon was modified by $10 \% \mathrm{HNO}_{3}$ for $12 \mathrm{~h}$ at the room temperature and repeatedly washed with de-ionized water, finally, the modified activated carbon was oven-dried at $85^{\circ} \mathrm{C}$ for $24 \mathrm{~h}$ to volatilize the organic impurities.

\section{Adsorbent synthesis}

The composite adsorbent used in this study was synthesized using a slightly modified procedure from that reported in the literature [24]. Briefly, the composite adsorbent was prepared from a suspension of the modified activated carbon in a $400 \mathrm{~mL}$ solution of $\mathrm{FeCl}_{3}(7.8 \mathrm{~g}$, $28 \mathrm{mmol})$ and $\mathrm{FeSO}_{4}(3.9 \mathrm{~g}, 14 \mathrm{mmol})$ at $70^{\circ} \mathrm{C}$. $\mathrm{NaOH}$ solution $(100 \mathrm{~mL}, 5 \mathrm{~mol} / \mathrm{L})$ was added dropwise to precipitate the iron oxides. Later, the obtained material was washed with de-ionized water until rinsing water became neutral, then the adsorbent was dried in an oven at $100^{\circ} \mathrm{C}$ for $8 \mathrm{~h}$ and finally stored in polystyrene bottles for further usage.

\section{Characterization}

The BET specific surface area and pore volumes of adsorbent before and after loading iron oxide were obtained by the cumulative adsorption of nitrogen at $77 \mathrm{~K}$ using a Micromeritics 2000 instrument (ASAP 2000, Micromeritics, USA). The point of zero charge (pHpzc) of iron oxide was obtained by interpolating the data to zero EM [31]. The morphologies of iron oxide/activated carbon composite and activated carbon were examined by a scanning electron microscope (SEM, Holland Philips, JSM-5800). X-ray diffraction pattern was taken from a $\mathrm{Cu}$ target X-ray diffractometer (Rigaku D/max-r B). 


\section{Batch adsorption experiments}

A batch technique was used to investigate $\mathrm{As}(\mathrm{V})$ adsorption. Batch experiments included: the kinetic studies, adsorption isotherms and some operating parameters.

The adsorption capacities of activated carbon and iron oxide/activated carbon composite were determined by batch adsorption isotherms at room temperature $\left(20 \pm 1^{\circ} \mathrm{C}\right)$ in aqueous solution. In several glass vials, $100 \mathrm{~mL}$ of solution containing various $\mathrm{As}(\mathrm{V})$ concentrations (50, 100, 150, $200,250 \mathrm{mg} / \mathrm{L}$ ) were contacted with $5.0 \mathrm{~g} / \mathrm{L}$ of adsorbent. The vials were placed in a water bath at $20^{\circ} \mathrm{C}$ and shaken at $150 \mathrm{r} / \mathrm{min}$ for approximately $24 \mathrm{~h}$ to ensure equilibrium was reached, and the $\mathrm{pH}$ was adjusted by adding $0.1 \mathrm{~mol} / \mathrm{L}$ $\mathrm{NaOH}$ or $\mathrm{HNO}_{3}$ until it remained constant $( \pm 0.10)$. After filtration through a $0.22 \mu \mathrm{m}$ membrane filter, the $\mathrm{As}(\mathrm{V})$ concentration of the filtered solutions was analyzed with an atomic fluorescence spectrometer (AFS) (PS Analytical Ltd., Kent, UK).

The adsorption kinetic study was performed for $\mathrm{As}(\mathrm{V})$ in solution at $\mathrm{pH} 6.0$ and room temperature $\left(20 \pm 1^{\circ} \mathrm{C}\right)$. Several glass vials were used to hold $50 \mathrm{~mL} \mathrm{As}(\mathrm{V})$ solution of known initial concentration $(2,5$, and $10 \mathrm{mg} / \mathrm{L})$ and $5.0 \mathrm{~g} / \mathrm{L}$ of composite adsorbent, and shaken at $150 \mathrm{r} / \mathrm{min}$ for a duration ranging from 0 to $240 \mathrm{~min}$. At certain period of time, each vial was removed from the shaker, and the solution was then filtered through 0.22 micron filter paper. The filtrates were analyzed for residual $\mathrm{As}(\mathrm{V})$ concentration with an atomic fluorescence spectrometer (AFS) coupled with a hydride generator. Arsenic concentration was determined by treating the solution with a reducing agent containing 5\% thiourea and $5 \%$ ascorbic acid prior to hydride generation and AFS measurement, using a solution containing $1.5 \% \mathrm{KBH}_{4}$ and $0.3 \% \mathrm{NaOH}$ as reducing solution and $1 \% \mathrm{HCl}$ as carrier solution.

To determine the effects of different parameters on As (V) adsorption, experiments were performed at various initial $\mathrm{pH}$, ranging between 2 and 11. Initial concentration of $10 \mathrm{mg} / \mathrm{L}$ of $\mathrm{As}(\mathrm{V})$ and composite adsorbent dosage $5.0 \mathrm{~g} / \mathrm{L}$ were employed. The effects of adsorbent dosage and contact time were conducted.

\section{Results and discussion}

\section{Characterization of adsorbents}

The microstructure changes of pure iron oxide, pure activated carbon and iron oxide/activated carbon composite adsorbent were listed in Table 1. As shown in Table 1, the deposited iron oxide contributes to a decrease in the $\mathrm{N}_{2}$-BET surface area, total pore volume and average pore diameter. As iron oxide has a relatively small surface area and microporous volume $\left(62.8 \mathrm{~m}^{2} / \mathrm{g}\right.$ and $0.009 \mathrm{~cm}^{3} / \mathrm{g}$, respectively) its presence in the composites should cause a decrease in the surface area and microporous volume compared to pure activated carbon. The point of zero
Table 1 Microstructure of pure iron oxide, pure activated carbon and iron oxide/activated carbon composite

\begin{tabular}{llll}
\hline Sample & $\begin{array}{l}\mathbf{S}_{\text {BET }} \\
\left(\mathbf{m}^{2} / \mathbf{g}\right)\end{array}$ & $\begin{array}{l}\text { Average pore } \\
\text { diameter }(\mathbf{n m})\end{array}$ & $\begin{array}{l}\text { Total pore } \\
\text { volume }\left(\mathbf{c m}^{\mathbf{3}} \mathbf{g}\right)\end{array}$ \\
\hline iron oxide & 62.8 & 0.926 & 0.009 \\
Activated carbon & 1022.6 & 1.859 & 0.861 \\
Composite adsorbent & 678.3 & 1.688 & 0.632 \\
\hline
\end{tabular}

charge (pHpzc) of prepared iron oxide was found to be 7.9 .

Figure 1 shows the SEM micrographs of activated carbon and composite adsorbent. It could be found from Figure 1 that there are a few macropores in activated carbon, and small aggregates are observed from the general view of the composite, which appear brighter, supported on the darker surface of the activated carbon.

To obtain information on the crystal structure of the prepared composite adsorbent, X-ray diffraction patterns were measured. The XRD patterns of pure iron oxide

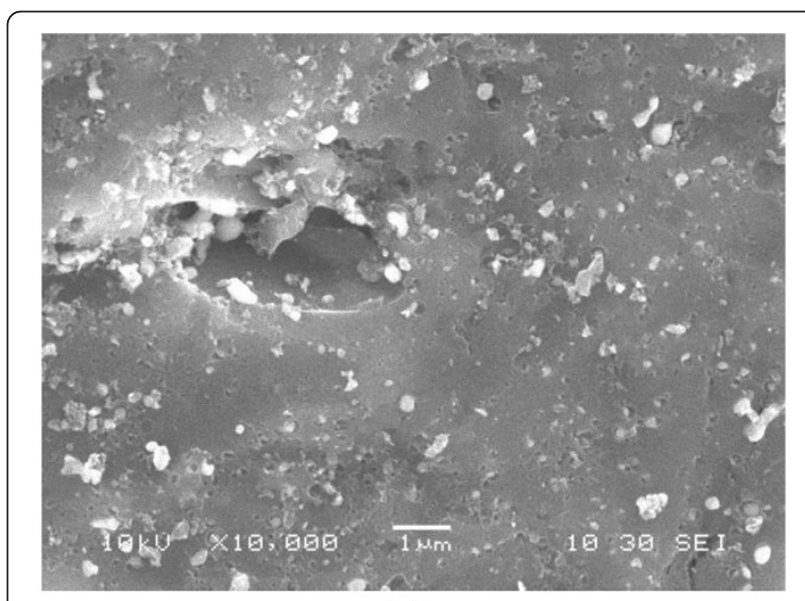

(a)

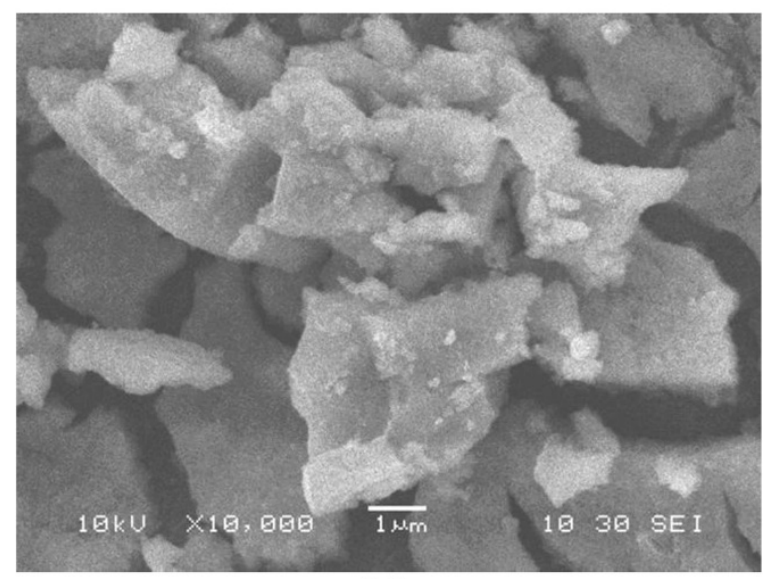

(b)

Figure 1 SEM micrographs of activated carbon (a) and iron oxide/activated carbon composite (b). 
and composite adsorbent were shown in Figure 2. XRD analyses of pure iron oxide suggest the presence of a cubic iron oxide phase, which may be related to the presence of maghemite $\left(\gamma-\mathrm{Fe}_{2} \mathrm{O}_{3}\right)$ and magnetite $\left(\mathrm{Fe}_{3} \mathrm{O}_{4}\right)$. So the prepared iron oxides are magnetic. For the composite the iron oxide maintained cubic spinel structure. This illuminated that the magnetic properties of iron oxide were basically invariable, which makes the composite adsorbent can be separated more easily by an applied magnetic filter. It could also be seen from Figure 2 that the peaks of cubic iron oxide phase in the composite appear broader, suggesting a smaller crystallite size.

\section{Effect of initial solution $\mathrm{pH}$}

The solution $\mathrm{pH}$ is an important factor for all water and wastewater treatment processes. Therefore, experiments were performed in order to investigate the effect of initial $\mathrm{pH}$ of solution to be treated regarding $\mathrm{As}(\mathrm{V})$. Figure 3 shows the percentage of $\mathrm{As}(\mathrm{V})$ removed as a function of $\mathrm{pH}$ value at $\mathrm{pH}=2.0 \sim 11.0$.

It is evident that the percentage of $\mathrm{As}(\mathrm{V})$ removal strongly depended on the media $\mathrm{pH}$. Furthermore, it can be noticed that the maximum adsorption capacities of composite adsorbent for $\mathrm{As}(\mathrm{V})$ occurred at $\mathrm{pH}$ 3.0-8.0. Nevertheless, the highest removal efficiency has taken place at pH 6.0 (95.27\%) which was chosen as an optimum $\mathrm{pH}$ condition for further experiments. The $\mathrm{As}(\mathrm{V})$ above the $\mathrm{pH}$ value of 3.0 is present in anionic forms and therefore, it can be effectively removed by the iron hydroxides, which at this $\mathrm{pH}$ range are present as cationic monomers $\left(\mathrm{Fe}(\mathrm{OH})_{2}^{+}\right)$[32]. Above $\mathrm{pH} 8.0 \mathrm{As}(\mathrm{V})$ removal was found to be decreased. This observation could be well correlated with the point of zero charge (PZC) of iron oxides. Pure iron oxides, whether they can be identified as having a

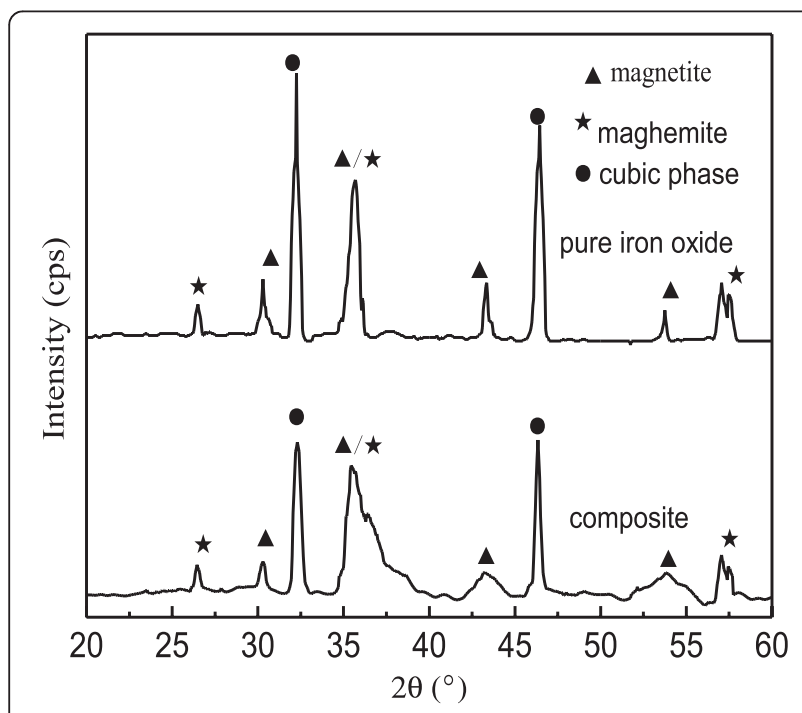

Figure 2 Powder XRD for pure iron oxide and iron oxide/activated carbon composite.

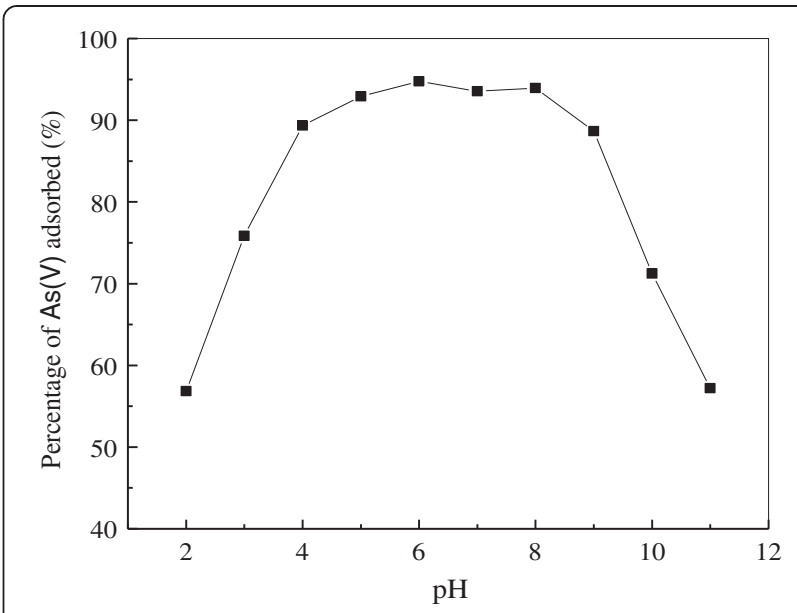

Figure 3 Effect of solution $\mathrm{pH}$ on the adsorption of $\mathrm{As}(\mathrm{V})$. (Experiment conditions employed: initial As(V) concentration $10 \mathrm{mg} / \mathrm{L}$, adsorbent dosage $5.0 \mathrm{~g} / \mathrm{L}$, adsorption time $1 \mathrm{~h}$, agitation speed $150 \mathrm{r} / \mathrm{min})$

particular crystal structure or not, typically have PZCs in the $\mathrm{pH}$ range 7.0-9.0 [33]. The point of zero charge (pHpzc) of the prepared iron oxide was found to be 7.9. Over the PZC value, iron oxide is present in the monomeric anionic form $\left[\mathrm{Fe}(\mathrm{OH})_{4}^{-}\right]$, hence inappropriate for adsorbing anionic components. So the removal of $\mathrm{As}(\mathrm{V})$ was suppressed by $\mathrm{Fe}(\mathrm{OH})_{4}^{-}$ions that surrounded the surface of the adsorbent by hindering the approach of As(V) to the adsorption sites present on the surface of adsorbent.

\section{Effect of adsorbent dosage}

The effect of adsorbent dosage on percentage adsorption of $\mathrm{As}(\mathrm{V})$ was shown in Figure 4. It could be seen from Figure 4 that the removal efficiency of $\mathrm{As}(\mathrm{V})$ considerably

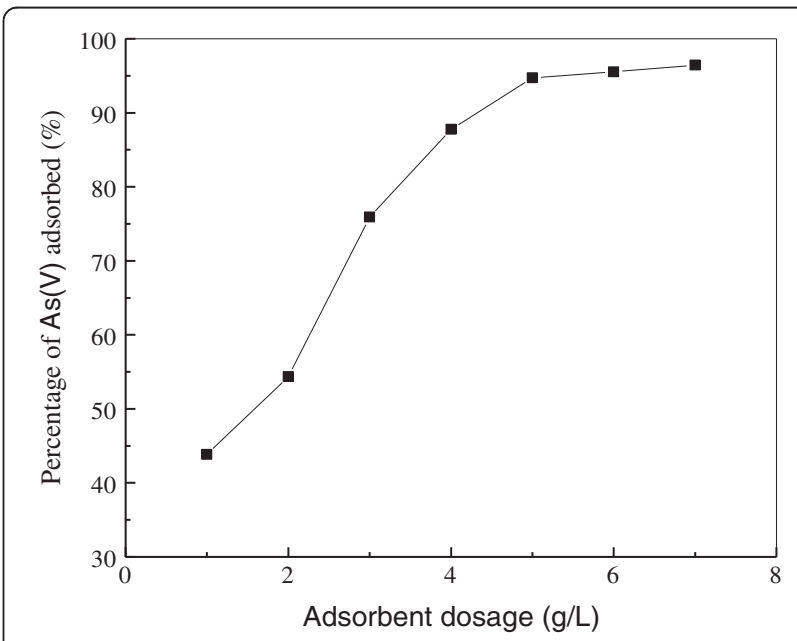

Figure 4 Effect of adsorbent dosage on the adsorption of As (V). (Experiment conditions employed: initial As $(M)$ concentration $10 \mathrm{mg} / \mathrm{L}$, solution $\mathrm{pH}$ 6.0, adsorption time 1 h, agitation speed $150 \mathrm{r} / \mathrm{min}$ ). 
increased with the increase of adsorbent dosage. The increase in adsorbent dosage from 1.0 to $5.0 \mathrm{~g} / \mathrm{L}$ resulted in an increase from 25.8 to $89.7 \%$ in adsorption of $\mathrm{As}(\mathrm{V})$. This may be due to the greater availability of the exchangeable sites or surface area at the higher concentrations of the adsorbent. On the other hand, the increase in the efficiency of removal may be attributed to the fact that with an increase in the adsorbent dosage, more adsorbent surface or more adsorption spots were available for the solute to be adsorbed $[3,15,34]$. A further increase in adsorbent dosage $(>5.0 \mathrm{~g} / \mathrm{L})$ did not cause significant improvement in $\mathrm{As}(\mathrm{V})$ adsorption. This may be due to the adsorption of almost all $\mathrm{As}(\mathrm{V})$ to the adsorbent and the establishment of equilibrium between the $\mathrm{As}(\mathrm{V})$ adsorbed to the adsorbent and those remaining unadsorbed in the solution. The results of this study are in accordance with obtained findings by other researchers $[2,3,15]$. Thus $5.0 \mathrm{~g} / \mathrm{L}$ of iron oxide/activated carbon composite adsorbent was chosen for next study.

\section{Effect of contact time}

Contact time is one of the effective factors in batch adsorption process. The effect of contact time on $\mathrm{As}(\mathrm{V})$ adsorption efficiency was shown in Figure 5. As it is shown, the removal efficiency of $\mathrm{As}(\mathrm{V})$ onto the composite adsorbent significantly increase during the initial adsorption stage (0-40 $\mathrm{min}$ ) and then continue to increase at a relatively slow speed with contact time until a state of equilibrium is attained after $60 \mathrm{~min}$. There was no significant change in $\mathrm{As}(\mathrm{V})$ removal rates after $1 \mathrm{~h}$ up to $3 \mathrm{~h}$. Based on these results, $1 \mathrm{~h}$ was taken as the time in adsorption experiments. Generally the removal rate of sorbate is rapid initially, but it gradually decreases with time until it reaches equilibrium. This phenomenon

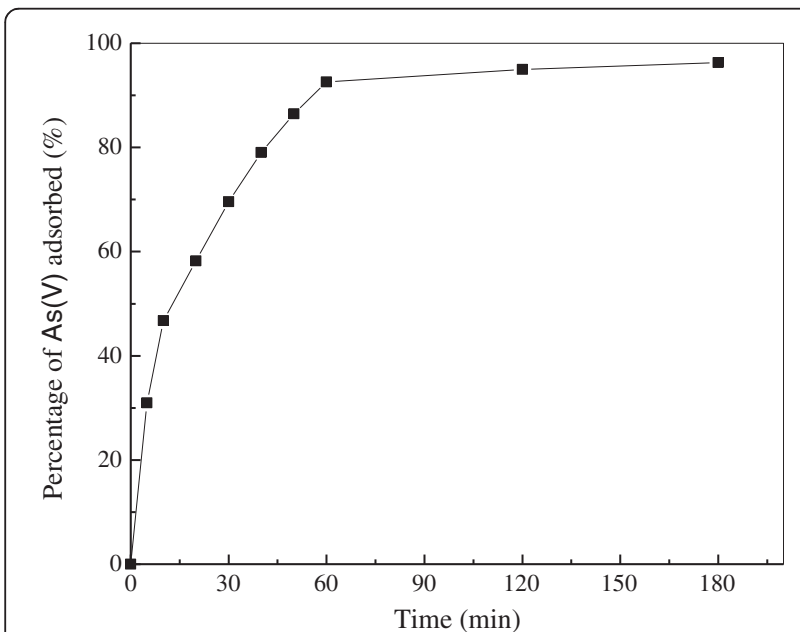

Figure 5 Effect of contact time on the adsorption of $\mathrm{As}(\mathrm{V})$. (Experiment conditions employed: initial As(V) concentration $10 \mathrm{mg} / \mathrm{L}$, adsorbent dosage $5.0 \mathrm{~g} / \mathrm{L}$, solution $\mathrm{pH}$ 6.0, agitation speed $150 \mathrm{r} / \mathrm{min}$ ). can be attributed to the fact that a large number of vacant surface sites are available for adsorption at the initial stage, and after a lapse of time, the remaining vacant surface sites are difficult to be occupied due to repulsive forces between the solute molecules on the solid and bulk phases. Similar findings were reported by other researchers $[3,35]$.

\section{Effect of co-existing anionic component}

In groundwater sources several anionic components might exist, which could compete with arsenic for the available adsorption sites. Among the major co-existing anionic components, sulfate $\left(\mathrm{SO}_{4}{ }^{2-}\right)$, phosphate $\left(\mathrm{PO}_{4}{ }^{3-}\right)$ and silicate $\left(\mathrm{SiO}_{3}{ }^{2-}\right)$ are usually present in groundwater streams possibly inhibiting arsenic removal. In order to investigate the effect of co-existing ions on $\mathrm{As}(\mathrm{V})$ removal, arsenic solutions were spiked with $\mathrm{SO}_{4}{ }^{2-}, \mathrm{PO}_{4}{ }^{3-}$ and $\mathrm{SiO}_{3}{ }^{2-}$, respectively and the removal of arsenic was determined. At fixed $\mathrm{pH}$ of 6.0, the effects of different anions (Figure 6) showed that phosphate or silicate caused the greatest percentage decrease in $\mathrm{As}(\mathrm{V})$ removal among the anions. Under the experimental conditions, phosphate resulted in a bigger decrease in $\mathrm{As}(\mathrm{V})$ removal than silicate. The effect of sulfate was minimal under the experimental conditions.

It is well known that silicate and phosphate strongly adsorb to metal oxide surfaces via inner-sphere complexation similar to the interaction mode of arsenate with metal oxides. The significant reduction in $\mathrm{As}(\mathrm{V})$ adsorption capacity in the presence of $\mathrm{SiO}_{3}{ }^{2-}$ and $\mathrm{PO}_{4}{ }^{3-}$ was due to the competition of the anions with $\mathrm{As}(\mathrm{V})$ for metal oxides adsorption sites. As $(\mathrm{V})$, silicate, and phosphate are adsorbed on metal oxides through the formation of surface complexes with the surface hydroxyl groups [36].

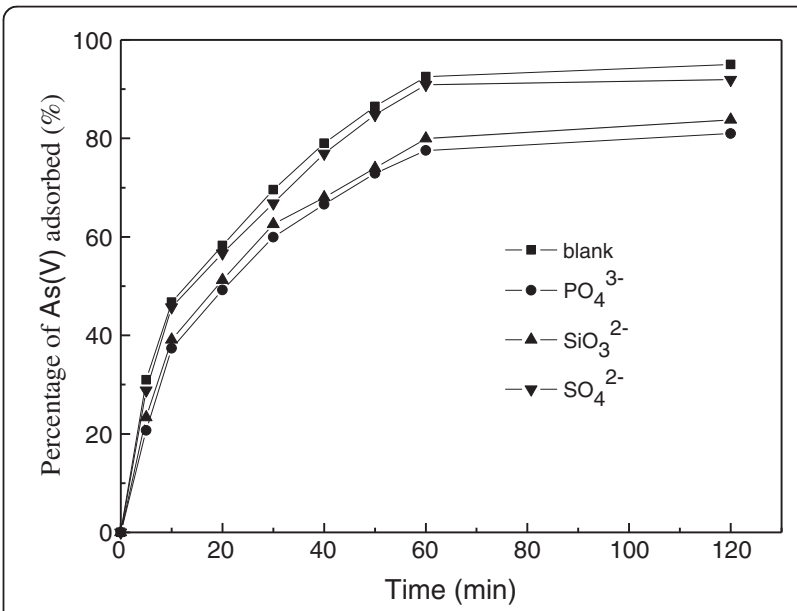

Figure 6 Effect of co-existing anionic component on the adsorption of $\mathbf{A s}(\mathbf{V})$. (Experiment conditions employed: initial $\mathrm{As}(\mathrm{V})$ concentration $10 \mathrm{mg} / \mathrm{L}$, adsorbent dosage $5.0 \mathrm{~g} / \mathrm{L}$, solution $\mathrm{pH}$ 6.0, agitation speed $150 \mathrm{r} / \mathrm{min}$ ). 
Sulfate can be absorbed by metal oxides both specifically and non-specifically via inner- and outer-sphere complexation. In addition, the sulfate binding affinity for metal oxides was much weaker than $\mathrm{As}(\mathrm{V})$ [37]. Hence, the removal of $\mathrm{As}(\mathrm{V})$ is most significantly affected by silicate and phosphate.

\section{Kinetic study}

In order to obtain the adsorption kinetic information of $\mathrm{As}(\mathrm{V})$ on the iron oxide/activated carbon composite adsorbent, the change of $\mathrm{As}(\mathrm{V})$ concentration with adsorption time was recorded for an initial concentration of $2,5,10 \mathrm{mg} / \mathrm{L}$. Figure 7 shows the adsorption percentage of $\mathrm{As}(\mathrm{V})$ on the composite adsorbent. Obviously, the adsorption is a rapid process, and the equilibrium is reached at $60 \mathrm{~min}$ for all three concentrations. For longer periods, adsorption trend seems to remain constant.

In order to investigate the mechanism of $\mathrm{As}(\mathrm{V})$ adsorption on the composite adsorbent, the pseudo-secondorder rate equation model was applied to the kinetic data. The pseudo-second-order kinetic equation could be derived as [38]:

$$
d q_{\mathrm{t}} / d t=k_{2}\left(q_{\mathrm{e}}-q_{\mathrm{t}}\right)^{2}
$$

Separating the variables in equation (1) gives

$$
-d\left(q_{\mathrm{e}}-q_{\mathrm{t}}\right) /\left(q_{\mathrm{e}}-q_{\mathrm{t}}\right)^{2}=k_{2} \cdot d t
$$

Integrating both sides for the boundary conditions $t=0$ to $t=t$ and $q_{\mathrm{t}}=0$ to $q_{\mathrm{t}}=q_{\mathrm{t}}$ gives the integrated rate law for a pseudo- second-order reaction,

$$
1 /\left(q_{\mathrm{e}}-q_{\mathrm{t}}\right)=1 / q_{\mathrm{e}}+k_{2} \cdot t
$$

Equation (3) can be rearranged to obtain:

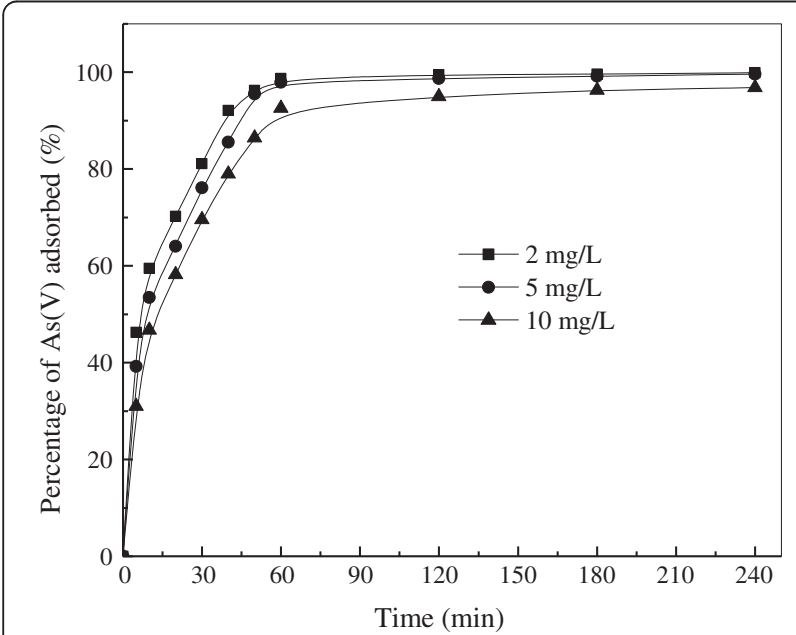

Figure 7 Adsorption kinetics of $\mathrm{As}(\mathrm{V})$ by iron oxide/activated carbon composite. (Experimental conditions employed: solution $\mathrm{pH}$ 6.0, agitation speed $150 \mathrm{r} / \mathrm{min}$, adsorbent dosage $5.0 \mathrm{~g} / \mathrm{L}$ ).
Table 2 Kinetic parameters for As(V) adsorption by iron oxide/activated carbon composite

\begin{tabular}{llll}
\hline $\boldsymbol{c}_{\mathbf{0}}(\mathbf{m g} / \mathbf{L})$ & $\boldsymbol{q}_{\mathrm{e}}(\mathbf{m g} / \mathbf{g})$ & $\boldsymbol{k}_{\mathbf{2}}(\mathbf{L} /(\mathbf{m g} \cdot \mathbf{m i n}))$ & $\mathbf{R}^{\mathbf{2}}$ \\
\hline 2 & 0.4123 & 0.4035 & 0.9996 \\
5 & 1.0389 & 0.1163 & 0.9994 \\
10 & 2.0716 & 0.0418 & 0.9995 \\
\hline
\end{tabular}

$t / q_{\mathrm{t}}=1 /\left(k_{2} \cdot q_{\mathrm{e}}^{2}\right)+t / q_{\mathrm{e}}$

The kinetic constant, $k_{2}$, can be determined by plotting of $t / q_{\mathrm{t}}$ against $t$.

The kinetic experimental data of $\mathrm{As}(\mathrm{V})$ on the composite adsorbent was simulated by pseudo-second-order rate equation (4). The results were listed in Table 2.

Remarkably, the kinetic data could be described well by the pseudo-second-order kinetic equation which was based on the assumption that the rate limiting step may be chemical sorption or chemisorptions involving valency forces through sharing or exchange of electron between adsorbent and adsorbate [39]. It could also be seen that the values of the pseudo-second-order rate constant decreased with increasing the initial As (V) concentrations.

\section{Adsorption isotherms}

The adsorption isotherm indicates how the adsorption molecules distribute between the liquid phase and the solid phase when the adsorption process reaches an equilibrium state. Langmuir and Freundlich isotherm equations are the most widely used models to describe the experimental data of adsorption isotherms. As(V)

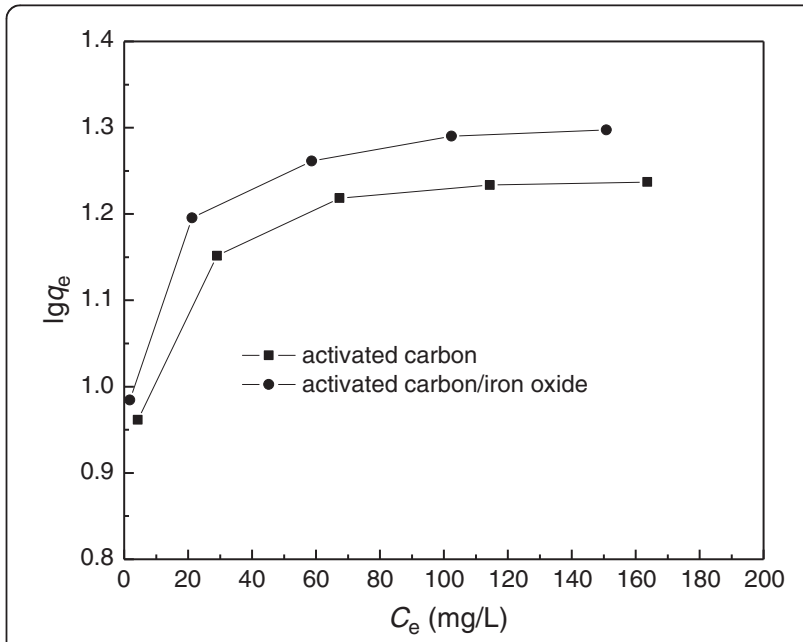

Figure 8 Adsorption isotherms of $\mathrm{As}(\mathrm{V})$ by iron oxide/activated carbon composite. (Experimental conditions employed: adsorbent dosage $5.0 \mathrm{~g} / \mathrm{L}$, solution pH 6.0, adsorption time 24 h, agitation speed $150 \mathrm{r} / \mathrm{min}$ ). 
Table 3 The parameters of Langmuir and Freudlich equation

\begin{tabular}{|c|c|c|c|c|c|c|}
\hline \multirow[t]{2}{*}{ Adsorbent } & \multicolumn{3}{|c|}{ Langmuir equation } & \multicolumn{3}{|c|}{ Freundlich equation } \\
\hline & $q_{m}(\mathrm{mg} / \mathrm{g})$ & B (L/mg) & $\mathrm{R}^{2}$ & $1 / \mathrm{n}$ & $\mathrm{K}_{\mathrm{f}}$ & $\mathrm{R}^{2}$ \\
\hline Activated carbon & 17.86 & 0.1816 & 0.9998 & 0.1808 & 7.3161 & 0.9806 \\
\hline Iron oxide/activated carbon & 20.24 & 0.2502 & 0.9996 & 0.1642 & 9.1806 & 0.9831 \\
\hline
\end{tabular}

adsorption isotherms obtained for activated carbon and iron oxide/activated carbon composite adsorbent were shown in Figure 8. These isotherms represent the adsorption behavior of $\mathrm{As}(\mathrm{V})$ on the different adsorbents as a function of increasing aqueous $\mathrm{As}(\mathrm{V})$ concentration for a contact time of $24 \mathrm{~h}$. All the isotherms show that the adsorption capacity increases with increasing equilibrium concentration of $\mathrm{As}(\mathrm{V})$, but the increasing slope of iron oxide/activated carbon composite adsorbent is higher than that of activated carbon.

The results of $\mathrm{As}(\mathrm{V})$ adsorption on all adsorbents (Figure 8) were analyzed by using the Langmuir model to evaluate parameters associated to the adsorption behavior. The linear form of Langmuir equation at a given temperature is represented by:

$$
q_{\mathrm{e}}=q_{\mathrm{m}} \cdot \mathrm{b} \cdot c_{\mathrm{e}} /\left(1+\mathrm{b} \cdot c_{\mathrm{e}}\right)
$$

where $c_{\mathrm{e}}$ is the aqueous phase ion equilibrium concentration $(\mathrm{mg} / \mathrm{L}), q_{\mathrm{e}}$ is the amount of $\mathrm{As}(\mathrm{V})$ sorbet onto $1 \mathrm{~g}$ of the considered adsorbent $(\mathrm{mg} / \mathrm{g})$, b is the adsorption constant $(\mathrm{L} / \mathrm{mg})$ related to the energy of adsorption and $q_{\mathrm{m}}$ is the maximum adsorption capacity $(\mathrm{mg} / \mathrm{g})$.

Equation (5) can be rearranged to obtain:

$$
c_{\mathrm{e}} / q_{\mathrm{e}}=1 /\left(\mathrm{b} \cdot q_{\mathrm{m}}\right)+c_{\mathrm{e}} / q_{\mathrm{m}}
$$

Experimental isotherm data acquired were correlated with the linear form of Langmuir model. The isotherm parameters related to the model were listed in Table 3 . It could be seen that both $q_{\mathrm{m}}$ and b remain the higher for $\mathrm{As}(\mathrm{V})$ adsorption onto iron oxide/activated carbon composite. This implies iron oxide/activated carbon composite has a higher adsorption of $\mathrm{As}(\mathrm{V})$ than pure activated carbon. High value of $\mathrm{b}$ was reflected in the steep initial slope of an adsorption isotherm, indicating desirable high affinity. Therefore, iron oxide/activated carbon performed well in $\mathrm{As}(\mathrm{V})$ adsorption.

The Freundlich isotherm model was also used to analyze the result of $\mathrm{As}(\mathrm{V})$ adsorption on different adsorbents (Figure 8). The Freundlich model can be expressed by the following equation:

$$
q_{\mathrm{e}}=k_{\mathrm{f}} \cdot c_{\mathrm{e}}^{1 / \mathrm{n}}
$$

where $k_{\mathrm{f}}$ and $\mathrm{n}$ are constants related to the adsorption capacity and affinity, respectively. The equation is conveniently used in the linear form by taking the logarithm of both sides as:

$$
\lg q_{\mathrm{e}}=\lg k_{\mathrm{f}}+(1 / \mathrm{n}) \lg c_{\mathrm{e}}
$$

Experimental isotherm data acquired on different adsorbents were fit with the linear form of Freundlich model and the isotherm parameters related to the model were listed in Table 3 . The data showed that the $k_{\mathrm{f}}$ constant is higher for iron oxide/activated carbon than that for activated carbon, $1 / \mathrm{n}$ value for iron oxide/activated carbon composite is smaller than that for pure activated carbon. These imply more favorable adsorption of As(V) on iron oxide/activated carbon composite.

\section{Conclusion}

A magnetic composite adsorbent was successfully prepared with activated carbon and iron oxide as raw materials for the removal of $\mathrm{As}(\mathrm{V})$ from solution. The performances of the composite adsorbent were compared to those of pure activated carbon, the composite adsorbent showed fast adsorption kinetics as well as high adsorption capacities. The adsorption properties of the composite adsorbent for $\mathrm{As}(\mathrm{V})$ depend on contact time, initial solution $\mathrm{pH}$, adsorbent dosage and co-existing anionic component. The adsorption kinetic data of $\mathrm{As}(\mathrm{V})$ can be illustrated very well by the pseudo-second-order rate equation. The equilibrium data obtained from this study was well presented by Langmuir and Freundlich models.

\section{Competing interests}

The authors declare that they have no competing interests.

\section{Authors' contributions}

YSH was the main investigator, collected the data, performed the statistical analysis, and drafted the manuscript. LZR carried out detailed adsorption and kinetic studies and their interpretation. SZL had done the quantitative analysis of arsenic, extended help in other laboratory studies related to the manuscript and supervised the study. All authors read and approved the final manuscript.

\section{Acknowledgments}

The authors gratefully acknowledge financial support for this work from the National Natural Science Foundation of China (41373127) and Liaoning Provincial Natural Science Foundation of China (2013020121).

\section{Author details}

'School of Applied Chemistry, Shenyang University of Chemical Technology, Shenyang, China. ${ }^{2} \mathrm{GE}-\mathrm{HE}$ Wind Energy (Shen Yang) Co., Ltd, Shenyang, China. 
Received: 28 August 2013 Accepted: 26 February 2014

Published: 6 March 2014

\section{References}

1. Smedley PL, Kinniburgh DG: A review of the source, behaviour and distribution of Arsenic in natural waters. Appl Geochem 2002, 17:517-568.

2. Li Q, Xu XT, Cui H, Pang J, Wei ZB, Sun Z, Zhai J: Comparison of two adsorbents for the removal of pentavalent arsenic from aqueous solutions. J Environ Manage 2012, 98:98-106.

3. Kord Mostafapour F, Bazrafshan E, Farzadkia M, Amini S: Arsenic removal from aqueous solutions by Salvadora Persica stem ash. J Chem 2013, 2013:1-8. 740847.

4. Tallman DE, Shaikh AU: Redox stability of inorganic arsenic(III) and arsenic (V) in aqueous solution. Anal Chem 1980, 52:199-201.

5. Cullen WR, Reimer KJ: Arsenic speciation in the environment. Chem Rev 1989, 89:713-764.

6. Hudak PF: Nitrate, arsenic and selenium concentrations in the pecos valley aquifer, West Texas, USA. Int J Environ Res 2010, 4:229-236.

7. WHO: Guidelines for Drinking-water Quality: Recommendations. 3rd edition. Geneva: World Health Organization; 2008.

8. FW P, Brown KG, Chen CJ: Health implications of arsenic in drinking water. J AWWA 1994, 86:52-63.

9. Su C, Puls RW: Arsenate and arsenite removal by zerovalent iron: kinetics, redox transformation, and implications for in situ groundwater remediation. Environ Sci Technol 2001, 35:1487-1452.

10. Chen SL, Dzeng SR, Yang MH, Chiu KH, Shieh GM, Wai CM: Arsenic species in groundwaters of the blackfoot disease area, Taiwan. Environ Sci Technol 1994, 28:877-881.

11. Erdem M, Özverdi A: Lead adsorption from aqueous solution onto siderite. Sep Purif Technol 2005, 42:259-264.

12. Shukla SR, Pai RS, Shendarkar AD: Adsorption of $\mathrm{Ni}(\mathrm{II}), \mathrm{Zn}(\mathrm{II})$ and $\mathrm{Fe}(\mathrm{II})$ on modified coir fibres. Sep Purif Technol 2006, 47:141-147.

13. Yao SH, Lai H, Shi ZL: Biosorption of methyl blue onto tartaric acid modified wheat bran from aqueous solution. Iran J Environ Health Sci Eng 2012, 9:1-6.

14. Gallegos-Garciaa M, Ramírez-Muñiza K, Songa S: Arsenic removal from water by adsorption using iron oxide minerals as adsorbents: a review. Mineral Processing \& Extractive Metall Rev 2012, 33:301-315.

15. Bazrafshan E, Faridi H, Kord Mostafapour F, Mahvi AH: Arsenic removal from aqueous environments using Moringa Peregrina seed extract as a natural coagulant. Asian J Chem 2013, 25:3557-3561.

16. El Qada EN, Allen SJ, Walker GM: Adsorption of methylene blue onto activated carbon produced from steam activated bituminous coal: a study of equilibrium adsorption isotherm. Chem Eng J 2006, 124:103-110.

17. Kouakou U, Ello AS, Yapo JA, Trokourey A: Adsorption of iron and zinc on commercial activated carbon. J Environ Chem Ecotoxicol 2013, 5:168-171.

18. Abechi ES, Gimba CE, Uzairu A, Kagbu JA: Kinetics of adsorption of methylene blue onto activated carbon prepared from palm kernel shell. Arch App/ Sci Res 2011, 3:154-164.

19. Tefera DT, Lashaki MJ, Fayaz M, Hashisho Z, Philips JH, Anderson JE, Nichols M: Two-dimensional modeling of volatile organic compounds adsorption onto beaded activated carbon. Environ Sci Technol 2013, 47:11700-11710.

20. Ruthven DM: Principles of Adsorption and Adsorption Processes. New York: Wiley; 1984.

21. Baup S, Jaffre C, Wolbert D: Adsorption of pesticides onto granular activated carbon: determination of surface dif fusivities using simple batch experiments. Adsorption 2000, 6:219-228.

22. Jung MW, Ahn KH, Lee Y, Kim KP, Rhee JS: Adsorption characteristics of phenol and chlorophenols on granular activated carbons (GAC). Microchem J 2001, 70:123-131.

23. Denizli A, O" zkan G, Ucar M: Removal of chlorophenols from aquatic systems with dye-affinity microbeads. Sep Purif Technol 2001, 24:255-262.

24. Oliveira LCA, Rios RVRA, Fabris JD, Garg V, Sapag K, Lago RM: Activated carbon/iron oxide magnetic composites for the adsorption of contaminants in water. Carbon 2002, 40:2177-2183.

25. Zhang HL, Li XC, He GH, Zhan JJ, Liu D: Preparation of magnetic composite hollow microsphere and its adsorption capacity for basic dyes. Ind Eng Chem Res 2013, 52:16902-16910.

26. Danková Z, Mockovčiaková A, Orolínová M: Cd(II) adsorption by magnetic clay composite under the ultrasound irradiation. Energy Environ Eng 2013, $1: 74-80$.
27. Ahsan N, Faruque K, Shamma F, Islam N, Akhand AA: Arsenic adsorption by bacterial extracellular polymeric substances. Bangladesh J Microbiol 2011, 28:80-83.

28. Mertens J, Rose J, Kägi R, Chaurand P, Plötze M, Wehrli B, Furrer G: Adsorption of arsenic on polyaluminum granulate. Environ Sci Technol 2012, 46:7310-7317.

29. Nasseri S, Heidari M: Evaluation and comparison of aluminum-coated pumice and zeolite in arsenic removal from water resources. Iran J Environ Healt Sci Eng 2012, 9:38.

30. Darban AK, Kianinia Y, Taheri-Nassaj E: Synthesis of nano-alumina powder from impure kaolin and its application for arsenite removal from aqueous solutions. J Environ Healt Sci Eng 2013, 11:19.

31. Goldberg S, Johnston CT: Mechanisms of arsenic adsorption on amorphous oxides evaluated using macroscopic measurements, vibrational spectroscopy, and surface complexation modeling. J Colloid Interf Sci 2001, 234:204-216.

32. Katsoyiannis IA, Zouboulis Al: Removal of arsenic from contaminated water sources by sorption onto iron-oxide-coated polymeric materials. Water Res 2002, 36:5141-5155.

33. Benjamin MM, Sletten RS, Bailey RP, Bennet T: Sorption and filtration of metals using iron-oxide coated sand. Water Res 1996, 30:2609-2620.

34. Pandey PK, Choubey S, Verma Y, Pandey M, Chandrashekhar K: Biosorptive removal of arsenic from drinking water. Bioresource Technol 2009, 100:634-637.

35. Gulnaz O, Sahmurova A, Kama S: Removal of reactive red 198 from aqueous solution by Potamogeton crispus. Chem Eng J 2011, 174:579-585.

36. Goldberg S: Chemical modeling of anions competition on goethite using the constant capacitance model. Soil Sci Soc Am J 1985, 49:851-856.

37. Meng XG, Bang SB, Korfiatis GP: Effects of silicate, sulfate, and carbonate on arsenic removal by ferric chloride. Water Res 2000, 34:1255-1261.

38. Ho YS, McKay G: Pseudo-second-order model for lead ion sorption from aqueous solutions onto palm kernel fiber. J Hazard Mater B 2006, 129:137-142.

39. Ho YS, McKay G: The kinetics of sorption of divalent metals ions onto sphagnum moss peat. Water Res 2000, 34:735-742.

doi:10.1186/2052-336X-12-58

Cite this article as: Yao et al:: Arsenic removal from aqueous solutions by adsorption onto iron oxide/activated carbon magnetic composite. Journal of Environmental Health Science \& Engineering 2014 12:58.

\section{Submit your next manuscript to BioMed Central and take full advantage of:}

- Convenient online submission

- Thorough peer review

- No space constraints or color figure charges

- Immediate publication on acceptance

- Inclusion in PubMed, CAS, Scopus and Google Scholar

- Research which is freely available for redistribution

Submit your manuscript at www.biomedcentral.com/submit 